\title{
Prospects of Coaching \& Mentoring as HRD Intervention in Pakistan: A Conceptual Study
}

\author{
Farooq-E-Azam Cheema * \\ Institute of Business \& Technology (IBT). \\ Khalili-ur-Rehman Bhatti * \\ University of Sindh, LAAR Campus, Badin. \\ Shoaib Ahmed * \\ Iqra University, Karachi. \\ Rajkumar * \\ Iqra University, Karachi.
}

\begin{abstract}
Purpose-Purpose of this conceptual study was to explore prospects of coaching and mentoring as a HRD intervention in the private sector organizations and government departments in Pakistan. This study was prompted by coaching and mentoring being an effective and efficient mode of employee development compared to traditional off-the-job classroom training programs.

Methodology/Sampling-The study was based on comprehensive literature reviewed critically and the diverse factors affecting these two activities as tools of employee development identified including their pre-requisites and possible barriers in the way of their introduction and application. The guidelines emerging from the relevant literature were used to make analysis of the internal and external organizational environments and Pakistani culture as a whole. Opinion on the national and organizational culture and other determining factors for the coaching and mentoring as HRD tool was based on wider observation and experience of the authors themselves.

Findings-The study did not promise rosy prospects altogether. It concluded that factors like organizational and national cultures, line managers' attitude towards coaching and mentoring and the top managements' overall approach towards the human resource development did not favour introduction and practice of coaching and mentoring as HRD intervention in Pakistan; both private sector local organizations as well as government sector departments.

Practical implications-The study is informative for the HRD practitioners who are ambitious in availing the contemporary HRD interventions including coaching and mentoring in Pakistan like society.
\end{abstract}

Keywords : Coaching, Mentoring, HRD Iintervention, Organizational Culture, Line Managers' Role

* The material presented by the author does not necessarily portray the viewpoint of the editors and the management of the Institute of Business \& Technology (IBT) or Business Administration in the University of Sindh, LAAR Campus and Iqra University, Karachi.

*Farooq-E-Azam Cheema : dr.cheema@biztekian.com

* Khalili-ur-Rehman Bhatti : bhattikrb@yahoo.com

* Shoaib Ahmed : ah.shuaib@gmail.com

*Rajkumar : raj.biztek@gmail.com

C JMSS is published by the Institute of Business \& Technology (IBT).

Main Ibrahim Hydri Road, Korangi Creek, Karachi-75190, Pakistan. 


\section{INTRODUCTION}

This study is part of a wider work the authors are engaged in with an emphasis on promotion of experiential learning in Pakistan. Western organizations and HRD practitioners have explicitly endorsed experiential learning as the contemporary HRD tool with its proven effectiveness and efficiency. Accordingly, they are fast moving away from the traditional classroom trainings and putting more premiums on workplace curricula and delivery. Authors like Pfefer and Sutten (1999), Twersky, (2001) and Harrison, (2005) say that integrating the learning more closely to the work combining knowing with the doing replacing the theoretical study with the competency based learning, and making the process of employee development less formal and cost effective, are the stark challenges that the contemporary HRD is facing.

This paradigm shift puts the premium on the experiential learning (Honey \& Mumford, 1989) or learning-through-doing (Howells, 1995) and concomitantly moves the emphasis towards the line managers assigning them the crucial role of employee development (Walton, 1999). Of course coaching and mentoring are the HRD interventions that promote experiential learning, and an increase in focus of the HRD practitioners and HRD oriented organizations over them has been noticed in the developed countries organizations more particularly. Stafylarakis \& Eldridge (2005) say that no doubt coaching and mentoring have always been associated with the HRD but in order to promote the learning within the organization they are now being used much more extensively across all the levels of the organization.

Coaching and mentoring cannot be interchanged in practice (Veale \& Wachtel, 1996). Rather, they have their own characteristic efficacy in separate areas of the HRD so they both of them are needed to be adopted as tools of the employee development in their own areas (ibid). Agreeing with the writer (ibid) we believe in optimum employment of the both instead of one as a replacement of the other. So in this study, first of all, we will be defining coaching and mentoring separately with their brief role in the HRD. Then difference between the two will be highlighted so that each could be utilised appropriately. Next to it, we will discuss different coaching and mentoring styles with explanation of their compatibility to the given situation. And at the end, the hurdles that the local private sector organizations and the government sector departments could face in introducing the mentoring and coaching program will be discussed.

\section{COACHING AND ITS ROLE IN HRD}

Coaching is a process in which a manager helps a colleague to solve on-the-job problem(s) (Megginson \& Boydell, 1979), to perform an increasing range of tasks (Torrington et. al 2002), and improve her/his job performance through creating self-awareness about learning (Christopher et. al, 2004) by direct discussion (Megginson \& Boydell, 1979), asking searching questions, actively listening, exhortation, encouragement, counselling, and providing information and honest feedback (Torrington et. al 2002), on the partnership relationship basis (Vint et. al 1998).

Phillips (1996) says that coaching has most of the time an unacknowledged management tool. However, situation is changing now. Fruits of coaching as tool of HRD have started emerging and it has started gaining popularity as a unique employee development intervention. We agree with the proposition of uniqueness of coaching as a tool of HRD that. This uniqueness distinguishes it from the traditional classroom trainings. The learning process that coaching entails occurs on-the-job so that the work itself rather than a lab designed simulated exercise is the source of learning experience. The learning ensued out of this intervention is effective as well as efficient. It entails simultaneity of learning and application rather than requiring transfer of learning from the classroom to the workplace. 
This distinguishing feature of coaching entails the learners receive instant feedback about their performance provides them opportunity to quickly mend their mistakes. This speeds up the whole learning and performance improvement process. It is efficient in the sense that it does not require to remove the worker from the job to the classroom. Off-thejob trainings incur dual cost; direct cost in the form of trainer and classroom expenditures, and indirect cost in the form of workers remaining absent from the work. Furthermore, even on the job, the emphasis during coaching intervention is on the learner learning rather than the coach teaching (Phillips, 1996). It means the coachee is supposed to take initiative and the coach's style usually remains non-intrusive with focus on guiding and helping from remoteness.

Being essentially work-based and practical in nature (Dale, 1999; Vint et. al, 1998; Stafylarakis \& Aldridge, 2005), and having in-built elements of immediacy and simultaneity of the application of learning to the job (Christopher et. al, 2004), coaching is the most effective way of keeping pace with the developments taking place in the environment (Vint et. al 1998). It provides the organizations with the opportunity to undertake pre-emptive and proactive interventions (Kilburg 1996) relevant to the immediate needs of the individual or team (Stafylarakis \& Aldridge 2005). Bowerman (1999) succinctly delineate the benefits all three parties; coach, coachee and the organization can have from coaching adopted as HRD intervention, in the Table 1 below.

Table 1

Potential benefits of the coaching as HRD intervention to various stakeholders

\begin{tabular}{|c|c|c|}
\hline Benefits for Coaches & Benefits for Performers & Benefits for Organization \\
\hline $\begin{array}{l}\text { Network is a practice } \\
\text { field for developing } \\
\text { skills. }\end{array}$ & $\begin{array}{l}\text { Coachees select goal. } \\
\text { They experience goal } \\
\text { achievement on their } \\
\text { terms. }\end{array}$ & $\begin{array}{l}\text { Network becomes a learning laboratory. } \\
\text { Often coachees and coaches meet on their } \\
\text { own time, i.e. at lunch hour. }\end{array}$ \\
\hline $\begin{array}{l}\text { Coaches become more } \\
\text { skilled } \\
\text { atintercommunications } \\
\text { including listening, } \\
\text { questioning, and sharing. }\end{array}$ & $\begin{array}{l}\text { Opportunities to talk in } \\
\text { confidence to another } \\
\text { about issues of } \\
\text { importance. }\end{array}$ & $\begin{array}{l}\text { Builds business literacy as individuals } \\
\text { from different operating divisions are } \\
\text { paired up. Helps to make tacit knowledge } \\
\text { explicit. }\end{array}$ \\
\hline $\begin{array}{l}\text { Coaches begin to see } \\
\text { their role as learner as } \\
\text { well. }\end{array}$ & $\begin{array}{l}\text { They come to understand } \\
\text { that their role is not just } \\
\text { to be helped, but to } \\
\text { provide feedback to help } \\
\text { the coach improve. }\end{array}$ & $\begin{array}{l}\text { Starts to build the competency of learning } \\
\text { how to learn. Work is place to integrate } \\
\text { some of the learning. }\end{array}$ \\
\hline $\begin{array}{l}\text { As the coachee becomes } \\
\text { aware of possibilities, so } \\
\text { the coach becomes aware } \\
\text { of possibilities for } \\
\text { themselves. }\end{array}$ & $\begin{array}{l}\text { Coachees take action to } \\
\text { achieve the goal they } \\
\text { have established. They } \\
\text { achieve breakthroughs in } \\
\text { performance as well. }\end{array}$ & $\begin{array}{l}\text { Organizations benefit from energized, self- } \\
\text { reliant employees. The process is } \\
\text { generative and benefits the organization } \\
\text { through improved performance }\end{array}$ \\
\hline \multirow[t]{2}{*}{$\begin{array}{l}\text { Opportunities to become } \\
\text { coaches in the next round } \\
\text { also. }\end{array}$} & $\begin{array}{l}\text { Opportunities to become } \\
\text { coaches in next round. }\end{array}$ & $\begin{array}{l}\text { Higher self-esteem on the part of } \\
\text { employees leads to more creativity, and } \\
\text { involvement. Employees demonstrate } \\
\text { leadership. }\end{array}$ \\
\hline & $\begin{array}{l}\text { Closure is experienced. } \\
\text { Real issues/goals are } \\
\text { dealt with in real time. }\end{array}$ & $\begin{array}{l}\text { Many projects in organizations lack formal } \\
\text { closure. Lack of closure is draining. This } \\
\text { clear time frame is energizing. }\end{array}$ \\
\hline
\end{tabular}

Source: Bowerman, J. (1999) 
But the coaching cannot be claimed as a panacea for all HRD ills (Vint et al 1998) rather it should be used only when it is genuinely seen as the best way of helping an individual learn and develop (Christopher et. al, 2004). Nor should it be taken in isolation from the rests of the learning methods (Megginson \& Boydell, 1979). Instead, when coaching sits alongside the other forms of learning then it realizes greater benefits through bringing that learning to the job (Vint et. al 1998).

\section{Mentoring and its Role in HRD}

Mentoring is a process in which one person [mentor] is responsible for overseeing the career and development of another person [protégé] outside the normal manager/subordinate relationship (Clutterbuck, 1991). A mentor is someone who is concerned with a person's life's work (Megginson \& Clutterbuck, 1996) and helps her/him become what that she/he aspires to be through career and psychological support (Appelbaum, et. al, 1994).

Gregson (1994) says that mentoring is an endeavor to transmit proficiency and expertise from practiced members in an organization to the less experienced. It is mostly used as a "fast-track" support scheme wherein the senior members of the organization oversee the activity and performance of the more junior colleagues who have been identified as 'crown princes' - kings of tomorrow. For these crown-princes, mentoring is used as a holistic HRD intervention to develop diverse attributes and skills among them. To achieve this purpose, mentoring needs the activities like sponsorship, coaching, protection, exposure, counselling, friendship (Kram, 1985) and appraisal (Leibowitz et. al., 1986) to undetake. But in practice, since the mentor can assume a few of these functions, the process of mentoring may mean quite different things in different settings (Jackson, 1993).

Ragins and Kram (2007) take a more comprehensive view of the concept of mentoring and say that the mentors are supposed to contribute to the protégé on two dimensions; career building and psychosocial richness. Career building functions include promoting job related skills and behaviours of the mentees, patronizing their growth and advancement, and enhancing their outlook as a way to help them grow intrinsically as well as extrinsically along the hierarchy of the organization. Psychosocial richness functions include building behaviors, such as offering acceptance and providing friendship, that enhance the protégé's personal growth, identity and self-worth.

Eddy et al. (2003) say that efficacy of mentoring has been got divulged upon the organizations and a growing number of them have implemented formal mentoring programs. These programs are thought to benefit the organization, as well as the individual mentoring participants. Gregson (1994) add to it saying that the relationship between mentor and the protégé seems to form a bond that binds both parties to the organization. However, findings of Fagenson (1992) are worth mention at this stage. He is of the view that entering into the mentoring relationship as a protégé is not a random process to be opted by anyone. Not everyone is motivated to assume the role of protégé. Rather dispositional characteristics matter in this regard. For instance, individuals with high growth and achievement need level were more to have a mentor than those who were low in need for growth and achievement. Aryee et al. (1999) put the point in other way and found that the people with ambition to succeed showed more inclination towards protégé-initiated mentoring. The point was supported by Turban and Dougherty (1994) who say that the individuals with an internal locus of control were more likely to initiate mentoring relationships than those with an external locus of control.

Apart from personality and disposition based features, learning goal orientation has been also found in scores of studies as a factor behind the choice for entering into mentor-mentee relationship. For instance, Brett and Vande Walle (1999) suggest that the individuals with a learning goal orientation are more likely to want to participate in HRD activities especially the mentor-protégé relationship. Godshalk and Sosik (2003) say that 
mentoring is a growth and development driven process, and the people having a learning goal mindset have an inclination toward adopting mentoring as development tool. In the nutshell, it looks that formal mentoring programs will be particularly attractive to high growth need level and high learning goal-oriented people because these programs offer them the opportunity to learn new behaviours, skills, and competency.

However, at the end, just like coaching, mentoring should also not be taken as a panacea for all HRD ailments. It is not appropriate in all circumstances, nor is it necessarily superior to other forms of management development (Clutterbuck, 1991). Rather it is a process to be used alongside other forms of career progression. The people who rely on mentoring alone may be missing out on other important sources of career help (Shapiro et. al, 1988). Mentoring should not be taken as replacement for effective classroom training and other staff development scheme - but it can make them even more effective (Grgson, 1993).

\section{DIFFERENCE BETWEEN COACHING AND MENTORING}

Veale et al. (1996) say that the policymakers ought not to confound coaching with mentoring rather the difference between the two is critical to be comprehended since it has the policy implications in proper employment of these tools of the HRD according to the requirement of the situation.

\subsection{Mentoring has a Wider Remit}

Coaching has to do with filling of a particular knowledge gap only (Christopher et. al, 2004) whereas the mentoring is multifaceted, (Stafylarakis \& Aldridge 2005) and has a wider remit as compared to the coaching (Gregson, 1993). The key roles in mentoring process are coaching (Clutterbuck 1991, Clutterbuck \& Wynne 1991, Walton 1999); counselling, networking, and facilitating, (Clutterbuck \& Wynne 1991), advising, brokering, advocating and acting as a referral agent (Walton 1999). Resultantly, for coaching, mainly job-specific skills are needed (Stafylarakis \& Aldridge, 2005); by contrast, mentoring requires bouquet of technical, psychological and behavioural skills (Applebaum et. al 1994). In short, whereas coaching aims to increase employees' work performance, mentoring addresses a larger set of issues related to the protégé's life inside and outside the organization (Sketch, 2001).

\subsection{Hierarchical Vs. Non Hierarchical Relationship}

Mentoring works better if the roles of mentor and boss are not confused because the two roles can on occasions be contradictory (Clutterbuck 1991). Stafylarakis \& Aldridge (2005) explain this point comprehensively saying that the purpose of detachment of the two is to preclude the line managers' role, which is mainly concerned with meeting the targets, from infringing upon the trust and openness necessary for mentoring relationship.

\subsection{Short-Term Vs. Long-Term Orientation}

Coaching has a short-term orientation since it is more goal-specific than mentoring. Mentoring on the other hand is open ended, requiring exceptional and sustained effort not for a few weeks, but for a minimum of a year and on average two or three years (Clutterbuck 1991).

\subsection{Structured Vs Informal Nature}

Coaching is generally more structured in nature and meetings are to be scheduled regularly (http://www.brefigroup.co.uk/coaching/coaching_and_mentoring.html). Whereas mentoring can be more informal and meetings can take place as and when the mentee needs some advice, guidance or support (ibid). 


\subsection{Individual Vs Team Focus}

Coaching may involve either an individual coachee or a team, mentoring is always one-to-one process between two individuals (Stafylarakis \& Aldridge, 2005).

\section{COACHING AND MENTORING STYLES}

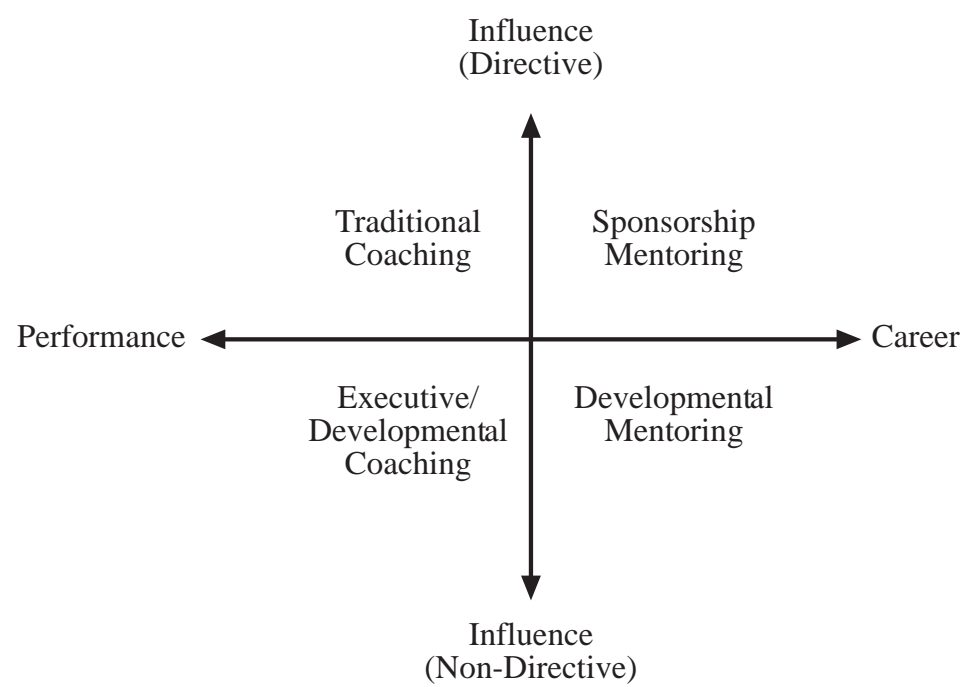

Source: Clutterbuck, 2006

The above model given by Clutterbuck (1991) comprehensively demonstrates different styles coaching and mentoring can adopt. These different styles have policy implications for the organizations that can apply these styles according to the requirement of the situation (Megginson \& Boydell, 1979; Sheal, 1999; Parsloe, 1992). The traditional coaching style also called as directive (Sheal, 1999) or 'hands-on' coaching style (Parsloe, 1992) tends to be most appropriate for new members of staff and those who are unfamiliar with a task or project where the coaches are needed to take decision and give instructions and then closely monitor the coachee to provide support (Sheal, 1999).

Executive/developmental coaching style also called as participatory (Sheal, 1999) or 'hands-off' coaching style (Parsloe, 1992) is more appropriate when the coach is coaching the experienced people who require only general guidance and monitoring, focussing more on joint problem-solving and providing general guidance rather than giving instructions (Sheal, 1999).

Similarly, sponsorship mentoring that is a paternalistic style of mentoring, (Gay, 1994) is appropriate at the 'telling' stage of the mentoring (Stafylarakis \& Aldridge. 2005) supposed to be for the rookies as against the developmental mentoring style normally for the managers.

\section{HURDLES IN COACHING AND MENTORING IN PAKISTAN}

But when contemplating coaching and mentoring programs as employee development interventions in Pakistani organizations we should not ignore the fact that mentoring and coaching are not straightaway functions to introduce easily. In this regard findings of Bowerman (1999) are informative. He says that coaching is not necessarily 
easy in an organization to introduce and implement. It is perhaps because it does not quickly fit with the traditional view of employee development. So, in this section of our work, we will identify certain widely discussed factors that impede the coaching and mentoring processes in the organizations and will try to correspond them with the Pakistan organizations context.

\subsection{Cultural Hurdles}

First hurdle in the way of introduction of coaching and mentoring as HRD tool is the Pakistani culture as a whole. Success of coaching and mentoring programs mainly depends upon culture of an organization wherein it is being practiced. They require a culture that is open and based on trust. They cannot work in the organizations where the culture is steeped in secrecy (Stafylarakis \& Aldridge, 2005). Gregson (1993) says that in terms of organizational framework, one must be sure that the organizations do have culture in which coaching and mentoring can effectively take place.

Bloch (1993) says that it is the relationship between mentor and mentee, and coach and coachee rather than a particular procedure or process, which establishes the foundation of coaching and mentoring programmes. This relationship should not be topdown or of directive style, putting the mentee of coachee through express instructions, rather should flow in move in an implied style towards inspiring the mentee's and coachee's thoughts and actions. Bowerman (1999) says that regardless of their formal status in the organization, once entered in coach-coachee or mentor-protégé relationship, role of both sides comes on even footing.

He says that the coachee/protégé must have full say in establishing such relationship. Trust is at the heart of coaching and mentoring, and it is the trust only that can spur commitment among the coachee/protégé that is a pre-requisite for success of this relationship. If coachee/protégé does not want to enter into such relationship then it must not occur. This cannot be directed to have it or requisitioned from the performers. Rather it must be educed only.

Whereas the culture in most of the organizations in Pakistan is characterised by the large power distance (Hofstede 1980) wherein the status conscious managers believe they are more important than their junior staff (Stafylarakis \& Aldridge 2005) and are more interested in lording powers over them than in achieving the organizational objectives through them (Misra 1994). Furthermore, they take the subordinates in the terms of Theory X (McGregor 1960) so they do not find worthwhile to put in the efforts needed to coach and develop them.

\subsection{Line Managers with Traditional Attitude Towards their Subordinates}

Attitude of line managers in Pakistani organizations whether private or government sector organizations does not suite requirements of coaching and mentoring as HRD tool. Coaching, particularly, is dependent upon the motivational level of the line managers (Dale, 1999; Walton, 1999), the management style they adopt and the way in which they view the staff (Sheal, 1999). But in our organization the line managers traditionally have an attitude of indifference towards development of their staff (Mann 1992; King 1992; Sheal 1999). For instance, as Kelly (1985) noted certain situations the line managers are generally facing like, "coaching is too time-consuming," "I can't suddenly change my role as a manager," and "It takes forever to realize any change" etc. Holding a gatekeeper role in respect of the provision of learning opportunities to their staff (Walton 1999), they mostly act negatively (Mann 1992) keeping that gate shut (Walton 1999) through following commonly known attitude (Mann, 1992; Sheal, 1999):

A. I haven't got enough time to spend on training people. I am already overloaded.

B. My boss never helped me how to do things. I learned it from myself and from 
my mistakes. So why should I have to worry about developing my people? C. Training and development is personnel or training department responsibility. It is nothing to do with me.

Foegen, (1998) says that fear on the part of management of losing power and control is highly associated with coaching. This is again true with the Pakistani culture. Control over employees has been traditionally a vital function of our managers.

Graham et al. (1993) referred to a technical area - span of control as a source of impediment in the way of caoching. He was of the view that larger span of control is a big hurdle in the way of introduction of coaching in developing countries organizations. Geber (1992) also pointed a technical reason against introduction of coaching and mentoring in developing countries organizations like Pakistan saying these activities are difficult to perform because the managers feel compelled to learn coaching and mentoring skills that they feel difficult to do because of dearth of time. McClean et al. (2003) say that the individuals who are both coaches and managers are caught by role conflict and role strain. They say that occupying the dual role of manager and coach seems to be a source of stress, and this is one of the main reasons that the managers in the organizations in the developing countries avoid entering into mentoring and coaching programs.

So, coaching and mentoring remain abandoned areas in local organizations in Pakistan. Time constraints and in-built adverse attitude of the managers are two major reasons as to why coaching is neglected. We have task-oriented organizational culture in Pakistan and our managers are always caught up by the deadlines remaining unable or at least not ready to spare some time away from the direct task to invest into HRD activities. Geber (1992) correctly says that in such scenario the employees also have difficulty in entering into coach-coachee relationship when the managers do not change their perceptions and make their attitude and behaviours development friendly.

\subsection{HRD People with Traditional Classroom Training Skills}

HRD in Pakistan had been through pedagogy (Knowles 1990), based on the traditional off-the-job training programs. The contemporary focus of experiential learning through doing threatens the traditional trainers (King, 1992). So due to fear of losing their status in the organization by getting delegated predominantly the training and development role to the line managers, the HRD people may not play their due role in promotion of the coaching (Stafylarakis \& Aldridge. 2005).

\subsection{Shortage of the Skilled Coaches and Mentors in Pakistan}

In Pakistani local organizations, coaching and mentoring programs cannot be started straightaway owing to non-availability of sufficient number of trained and skilled coaches and mentors. We can train the mangers/supervisors or certain senior employees as coaches (Megginson \& Boydell, 1979) but providing suitable mentors off hand will be difficult owing to dearth of the overall mentoring culture (Kram, 1985). Consequently, we will have to face the problem of mentor-mentee mismatch (Clutterbuck, 1991; Appelbaum et. al., 1994; Jackson, 1993) emanating from the forced couplings (Stafylarakis \& Aldridge, 2005) that we will have to do at the 'gun-point' (Clutterbuck, 1991) through 'get-on-withit' orders (Christopher et. al, 2004), in stead of promoting voluntarily relationship (Levinson et. al., 1978), which violates the true spirit of the mentoring (Appelbaum et. al., 1994).

\subsection{Low Preference for Human Resource Development in Pakistan}

One of the points of Browman (1999) is very much representative of the scenario in Pakistan. He says that coaching and mentoring require a level of professionalism and special ability that most of the line managers especially from the developing countries do not possess. So, initially they do not have other option but to require external expertise 
help organize and deliver the programs. Apart from that, line managers need continuous training in coaching and mentoring. We believe that effort should be made to build as much indigenous expertise in coaching and mentoring activities as possible. Gregson (1994) correctly says that some organizations naively assume that the process of mentoring means simply assigning a junior to a more senior colleague - and that the "natural" skills of the senior manager will allow him or her to become an effective mentor. It means the programs are not popular that do not have HRD at higher priority. Pakistan is among those countries whose organizations are spending only the peanuts on the employee development. So this could be one of the major hurdles in getting the coaching and mentoring like activities in Pakistani local organizations.

\section{CONCLUSION}

The emphasis on formal development and training programs in the organizations is declining in favor of the greater interest in approaches to on-the-job development worldwide. Consequently, coaching and mentoring are becoming increasingly popular as the most important on-the-job learning techniques. But it will be naïve to take coaching and mentoring as elixir to all the development related ailments. Rather, their success depends upon the needs and the culture of the organizations and on the extent to which these are dovetailed with the other modes of the HRD.

Keeping into view various factors, dimensions and pre-requisites relating to coaching and mentoring as tools of HRD, and the possible hurdles in their way, we could not find an environment conducive for their introduction and practicing in the local private sector or even in the government sector organizations of Pakistan. First factor that poses barrier to the implementation of coaching and mentoring as HRD tools is the organizational culture characterized by larger power distance that does not allow coach-coachee or mentor mentee like liberal and egalitarian relationship to occur and practiced.

Second factor is the low priority for human resource development as a whole in both local private sector organizations and the government sector departments. Line managers who are at the heart of coaching and mentoring program are themselves the third major hurdle in the way of success of coaching and mentoring programs in Pakistan. Their attitude is accumulatively muddied by the top-down culture, their preoccupation in goals achievement and their overall apathy towards subordinate development. So for introduction of coaching and mentoring like contemporary HRD tools in our organizations, we need fist of all a radical shift of our mindset towards human resource development as a whole, which till date is badly missing.

\section{BIBLIOGRAPHY}

1. Appelbaum, S., Ritchie, S. \& Shapiro, B. (1994) Mentoring Revisited: An Organizational Behavior Construct. Journal of Management Development, Volume 13 No. 4

2. Aryee, S., Lo, S., \& Kang, I. L. (1999) Antecedents of early career stage mentoring among Chinese employees. Journal of Organizational Behavior, 20

3. Bloch, S. (1993) The Mentor as Counsellor. Employee Counselling Today, Vol. 5 No. 3, 1993, pp. 9-10 (C) MCB University Press, 0955-8217.

4. Bowerman, J. (1999) The coaching network: a program for individual and organizational development. Journal of Workplace Learning, 11(8)

5. Brett, J. F., \& Vande Walle, D. (1999) Goal orientation and goal content as predictors of performance in a training program. Journal of Applied Psychology, 84

6. Clutterbuck, D. (1991) Everyone Needs a Mentor: Fostering talent at work, IPD

7. Cluuterbuck, D. \& Wyyne, B. (1991) Mentoring and coaching. Gower Handbook of Management Development, Gower 
8. Christopher, R, Michael, H. \& Geoff, H. (2004) A Practical Guide to Mentoring, Coaching, and Peer-networking: Teacher Professional Development in Schools and Colleges. Taylor \& Francis

9. Dale, M. (1999) Developing Management Skills Vol. 3 The Art of HRD. Crest Publishing House

10. Eddy, E., Tannenbaum, S., Alliger, G., D'Abate, C., \& Givens, S. (2003) Mentoring in industry: The top 10 issues when building and supporting a mentoring program. Paper presented at the 18th annual meeting of the Society of Industrial and Organizational Psychology, Orlando, Florida.

11. Fagenson, E. (1992) Mentoring: Who needs it? A comparison of protégés' and non-protégés' needs for power, achievement, affiliation, and autonomy. Journal of Vocational Behavior, 41

12. Foegen, J. H. (1998) Are managers losing control? Business Horizons, 41 (2)

13. Gay, B. (1994) 'What is Mentoring?' Education + Training, Vol. 36 (5)

14. Geber, B. (1992) From manager into coach, Training, 29 (2)

15. Godshalk, V. M., \& Sosik, J. J. (2003) Aiming for career success: The role of learning goal orientation in mentoring relationships. Journal of Vocational Behavior, 63

16. Graham, S., Wedman, J. F., \& Garvin-Kester, B. (1993) Manager coaching skills: Development and application. Performance Improvement Quarterly, 6 (1)

17. Gregson, K. (1993) Mentoring. Work Study Journal, Vol. 42 (6)

18. Gregson, K. (1994) Mentoring. Employee Counselling Today, Vol. 6(4)

19. Harrison, R. (2005) Learning and Development. Institute of Personnel and Development.

20. Honey, P. \& Mumford, A. (1989) A Manual of Learning Opportunities, Peter Honey

21. Howells, J. (1995), Tacit Knowledge and Technology Transfer, ESRC Centre for Business Research of Cambridge Journal, CBR Research Program Policy

22. Jackson, C. (1993) Mentoring: Choices for Individuals and Organizations, The International Journal of Career Management, Volume 5 No. 1

23. Kelly, P. J. (1985), Coach the coach, Training and Development Journal, 39 (11)

24. Kilburg, R. (1996) Towards a conceptual understanding and definition of executive coaching, Consulting Psychology Journal. Vol. 48, No. 2

25. King, W. (1992) Involving Managers in Staff Development: A Jamaican View, HRD: International Perspectives on Development and Learning, Kumarian Press

26. Knowles, M. (1990) The Adult learner: a neglected species, Gulf Publishing Company

27. Kram, K. (1985) Mentoring at Work: Developmental relationships in Organizational Life, University Pres of America

28. Landsberg, M. (1996) The Tao of Coaching: Boost your effectiveness at work by inspiring and developing those around you, Harper Collins

29. Leibowitz, Z., Farren, C., and Kaye, B. (1986) Designing Career Development Systems, Jossey-Bass

30. Levinson, D., Darrow, C. \& Klein, C., Levinson, M. \& Mckee, B. (1978) The Seasons of a Man's Life, Knopf

31. Mann, P. (1992) Structuring the Line Manager into HRD, HRD: International Perspectives on Development and Learning, Kumarian Press

32. McLean, G., Baiyin, Y., Min-Hsun, K, Tolbert, A. \& Larkin, C. (2003) Development and Initial Validation of an Instrument Measuring Managerial Coaching Skill, Human Resource Development Quarterly, Vol. 16(2)

33. Megginson, D. \& Boydell, T. (1979) A manager's guide to coaching, British Association of Commercial and Industrial Education

34. Meggison, D. \& Clutterbuck, D. (1996) Mentoring in Action - A Practical Guide for Managers, Kogan Page

35. Missirian, A. (1982) The corporate connection: why executive women need to reach the top, Prentice Hall

36. Parsloe, E. (1992) Coaching Mentoring and Assessing: a practical guide to 
developing competence, Kogan Page Ltd.

37. Pegg, M. (1999) The Art Of Mentoring. Industrial and Commercial Training, 31(4)

38. Phillips, R. (1996) Coaching for higher performance. Employee Counselling Today, Vol. 8

39. Pfefer and Sutten (1999) The Knowing-Doing Gap: How Smart Companies Turn Knowledge into Action, Harvard Business School Press

40. Ragins, B. R., \& Kram, K. E. (2007) The handbook of mentoring at work: Theory, research, and practice, Thousand Oaks, CA: Sage.

41. Shapiro, G. \& Farrow, D. (1988) Mentors and Others in Career Development. Women's career: Pathways and Pitfalls, Praeger

42. Sheal, P. (1999) Staff Development Vol. 6 The Art of HRD, Crest Publishing House

43. Sketch, E. (2001) Mentoring \& coaching help employees grow. HR Focus, 78(9).

44. Stafylarakis, M. \& Eldridge, D. (1995) HRD Definitions and Significance - unit 1 Human Resource Development IDPM

45. Torrington, D., Hall, L. and Taylor, S. (2002) Human Resource Management, Pearson Education Ltd.

46. Turban, D. B., \& Dougherty, T. W. (1994) Role of protégé personality in receipt of mentoring and career success. Academy of Management Journal, 37

47. Twersky, A (2001). The Knowing - Doing Gap. The TABS journal

48. Walton, J. (1999) Strategic Human Resource Development, Person Education Ltd.

49. Veale, J. \& Wachtel, J. (1996) Mentoring and coaching as part of a human resource development strategy: an example at Coca-Cola Foods. Management Development Review, Vol. 9(6)

50. Vint, A., Gould, D. \& Recaldin, C. (1998) Learning to Fly, Kogan Page Ltd.

51. http://www.brefigroup.co.uk/coaching/coaching_and_mentoring.html, visited on 7 th May, 2006 at 1.15 p.m. 